\title{
KOMBINASI METODE AHP DAN MFEP DALAM UPAYA MENINGKATKAN KUALITAS PENERIMA BANTUAN SISWA MISKIN
}

\author{
Andri Nata $^{1}$, Yori Apridonal ${ }^{1}$ \\ ${ }^{1}$ Sistem Informasi, Sekolah Tinggi Manajemen Infromatika dan Komputer Royal \\ email: andrinata0202@gmail.com
}

\begin{abstract}
The Poor Student Assistance Program is a government program aimed at removing barriers to poor students from participating in school to support the Nine-Year Compulsory Basic Education Program. According to TNP2K, the target of BSM recipients is based on the criteria of students' economic conditions and not on the achievements of students. The problem so far is not a few are found that BSM recipients are those who are classified as capable so that this program is not well-targeted. The purpose of applying the combination of 2 AHP and MFEP methods is to apply Decision Support System (SPK) technology in determining students who receive poor student assistance at Tamansiswa Sukadamai SMPS so that it helps decisionmakers to get objective decisions. The combination is based on the superiority of each method in analyzing each criterion and alternatives related to the selection of BSM recipients. AHP is used to analyze criteria to produce criteria that have a good consistency. Then an alternative ranking process is carried out using the MFEP method. Based on the results of the analysis of the combination of the AHP and MFEP methods that have been carried out that the AHP method can help schools in determining the main factors that are very priority in receiving poor student assistance, while the MFEP method can determine the best alternative for eligible students as recipients of poor student assistance in the form of ranking the highest value is A9 with 1,097 .
\end{abstract}

Keywords: AHP Method; MFEP Method; Poor Student Assistance; SPK.

\begin{abstract}
Abstrak: Program Bantuan Siswa Miskin (BSM) merupakan program pemerintah yang ditujukan untuk menghilangkan halangan siswa miskin berpartisipasi untuk bersekolah mendukung program Wajib Belajar Pendidikan Dasar Sembilan Tahun. Menurut TNP2K adapun yang menjadi sasaran penerima BSM yaitu berdasarkan kriteria kondisi ekonomi siswa dan bukan berdasarkan prestasi siswa. Permasalahan selama ini justru tidak sedikit dijumpai bahwa penerima BSM merupakan mereka yang tergolong mampu, sehingga program ini menjadi kurang tepat sasaran. Adapun tujuan dari penerapan kombinasi 2 metode AHP dan MFEP ini adalah untuk menerapkan teknologi Sistem Pendukung Keputusan (SPK) dalam penentuan siswa penerima bantuan siswa miskin di SMPS Tamansiswa Sukadamai sehingga membantu pengambil keputusan untuk mendapatkan keputusan yang objektif. Kombinasi dilakukan berdasarkan keunggulan dari masing-masing metode dalam menganalisis setiap kriteria dan alternative terkait pemilihan penerima BSM. AHP digunakan untuk menganilis kriteria sehingga menghasilkan kriteria yang memiliki konsistensi yang baik. Selajutnya dilakukan proses perangkingan alternatif menggunakan metode MFEP. Berdasarkan hasil analisis dari kombinasi metode AHP dan MFEP yang telah dilakukan bahwa metode AHP dapat membantu sekolah dalam menentukan faktor utama yang sangat prioritas dalam penerima bantuan siswa miskin, sedangkan metode MFEP dapat menentukan alternatif terbaik siswa yang layak sebagai penerima bantuan siswa miskin dalam bentuk perangkingan dengan nilai tertinggi yaitu A9 dengan 1,097.
\end{abstract}

Kata Kunci : Bantuan Siswa Miskin; Metode AHP; Metode MFEP; SPK. 
DOI: https://doi.org/10.33330/jurteksi.v6i2.597

Available online at http://jurnal.stmikroyal.ac.id/index.php/jurteksi

\section{PENDAHULUAN}

Bantuan Siswa Miskin (BSM) merupakan kebijakan pemerintah yang ditujukan untuk siswa yang tidak memiliki kemampuan secara ekonomi (siswa miskin) sehingga mendapatkan kesempatan sekolah selayaknya siswa lainnya. Kebijakan ini diharapkan berhasil meningkatkan partisipasi siswa dalam pendidikan yang memadai, sehingga siswa-siswa yang putus sekolah dapat kembali bersekolah. Selain itu, melalui program ini segala kebutuhan dalam proses belajar juga diperhatikan [1]-[4]. Berdasarkan data yang dirilis oleh Tim Nasinal Percepatan Penanggulangan Kemiskinan (TNP2K), dana bantuan yang siswa yang mendapatkan program ini yaitu dari mulai SD sampai pendidikan tinggi diberikan dana sejumlah $\mathrm{Rp} 225.000$ per semester sekolah dasar, Rp 375.000 per semester untuk sekolah menengah pertama, dan Rp 500.000 per semester untuk sekolah menengah atas. Menurut TNP2K yang menjalankan program ini, program BSM diarahkan bagi siswa yang tidak mampu secara ekonomi dalam membiayai kebutuhan yang berkaitan dengan pendidikannya. Sehingga siswa yang memiliki kemapuan secara ekonomi meskipun pintar, bukanlah yang dimaksudkan dalam program ini.

Akan tetapi, permasalahannya selama ini justru tidak sedikit dijumpai bahwa penerima BSM merupakan mereka yang tergolong mampu. Selain itu masih dijumpai mereka yang layak menerima bantuan justru tidak mendapatkannya[5], [6], Sehingga program ini menjadi kurang tepat sasaran. Hal ini terjadi akikbat pengambilan keputusan yang cenderung subyektif, kedekatan kekeluargaan dan lainnya.
Untuk itu perlu adanya penerapan teknologi yang dapat membantu pengambil keputusan untuk mendapatkan keputusan yang tepat sasaran.

Berdasarkan observasi yang dilakukan di sekolah SPM Swasta Tamansiswa Sukadamai, pihak sekolah selama ini terus berupaya memberikan bantuan BSM kepada siswa supaya tepat sasaran. Namun terkadang masih mengalami kesulitan dalam proses seleksi karena banyaknya siswa yang akan dinilai kelayakannya.

Berdasarkan permasalahan yang terjadi peneliti tertarik untuk menerapakan teknologi Sistem Pendukung Keputusan (SPK) dalam penentuan siswa perima bantuan siswa miskin di SMPS Tamansiswa Sukadamai. Adapun metode yang digunakan adalah kombinasi 2 metode yaitu Analitycal Hierarcy Process (AHP) dan Method Multy Factor Evaluation Process (MFEP). Kombinasi dilakukan berdasarkan keunggulan dari masing-masing metode dalam menganalisis setiap kriteria dan alternative terkait pemilihan penerima BSM. AHP digunakan untuk menganilis kriteria sehingga menghasilkan kriteria yang memiliki konsistensi yang baik. Setelah itu, selajutnya dilakukan proses perangkingan alternatif menggunakan metode MFEP. Sejauh ini teknik kombinasi metode ini belum ada dijumpai, sehingga diharapkan hasil yang didapatkan jauh lebih optimal.

Menurut Dwika Assrani dalam penelitiannya menjelaskan bahwa bantuan siswa miskin adalah program pemerintah dalam bidang pendidikan untuk memberikan hak pendidikan kepada siswa yang tidak memiliki kemampuan secara ekonomi [2]. Ukuran ketercapaian program ini adalah meningkatnya angka pastisipasi murni 
DOI: https://doi.org/10.33330/jurteksi.v6i2.597

Available online at http://jurnal.stmikroyal.ac.id/index.php/jurteksi

dan kasar (APM dan APM).

Sistem Pendukung Keputusan adalah sebuah sistem yang ditujukan untuk membantu pengambil keputusan dalam sebuah pertimbangan yang kompleks, sehingga diharapkan dapat memudahkan dalam proses pengambilan keputusan. Dalam pelaksanaannya, sebuah sistem pendukung keputusan dirancang secara komputerisasi agar memiliki fleksibilitas dalam melakukan analisis terhadap pertimbangan yang kompleks tersebut[7].

Analitycal Hierarchy Process (AHP) adalah metode dalam sistem pendukung keputusan yang melakukan identifikasi masalah hingga proses analisis secara hirarki. Pertama kali di perkenalkan oleh Thomas L Saaty di tahun 1980. Melalui konsep hirarki dan perbandingan berpasanagan, metode ini mampu menyajikan nilai konsistensi sebuah perbadingan sehingga memungkinkan untuk mendapatkan hasil yang lebih baik[8].

Dalam Prosesnya metode AHP memiliki beberapa prosedur yaitu [9]:

1. Membuat indentifikasi masalah yang disusun secara hirarki dimulai dari goal(tujuan), kriteria dan sub kriteria hingga altarnatif yang akan dinilai. Penyusunan secara hirarki ditujukan untuk mempermudah dalam memahami sebuah permasalahan.

2. Menyusun sebuah matriks perbandingan antar pasangan yang menunjukan hubungan kepentingan dalam mempengaruhi pencapain goal. Dalam AHP memiliki nilai yang dijadikan ukuran perbandingan dimulai dari 1 hingga 9. Setiap nilai memiliki makna tersendiri. Semakin besar sebuah nilai perbandingan maka semakin besar sebuah elemen mempengaruhi pencapaian goal.

3. Menentukan nilai eigen dari matriks perbandingan yang selanjutnya mengukur nilai konsistensi rasio dari matriks tersebut hingga nilai target konsistensi terpenuhi

4. Mengulangi langkah 2 dan 3 untuk untuk setiap tahapan hirarki.

5. Melakukan pemeriksaan konsistensi hirarki. Rumus Untuk Menentukan Consistensi Ratio (CR) dengan rumus $\mathrm{CR}=\mathrm{CI} / \mathrm{IR}$

Nilai Consistensi Index dari matriks berordo $\mathrm{n}$ dapat diperoleh dengan rumus:

$\mathrm{CI}=(\lambda$ maks $-\mathrm{n}) / \mathrm{n}$

dimana:

$\mathrm{CI}=$ Indek konsistensi (Consistency Index)

$\lambda=$ Nilai eigen terbesar dari matrik berordo $\mathrm{n} \lambda$ maksimum didapat dengan menjumlahkan hasil perkalian jumlah kolom dengan eigen vektor utama.

Tabel 1. Tabel Indeks Random

\begin{tabular}{cc}
\hline $\mathbf{N}$ & $\mathbf{R I}$ \\
\hline 1 & 0.00 \\
\hline 2 & 0.00 \\
\hline 3 & 0.58 \\
\hline 4 & 0.90 \\
\hline 5 & 1.12 \\
\hline 6 & 1.24 \\
\hline 7 & 1.32 \\
\hline 8 & 1.41 \\
\hline 9 & 1.45 \\
\hline 10 & 1.49 \\
\hline 11 & 1.51 \\
\hline 12 & 1.58
\end{tabular}

Apabila $\mathrm{CR}=0,1$ matriks berpasangan dinyatakan konsisten, jika tidak maka proses harus diulangi. Untuk 
nilai indeks random(RI) yang ditetapkan oleh Saaty yang bergantung pada ordo matrik $\mathrm{n}$ pada tabel 1 .

Metode MFEP (Multi Factor Evaluation Process) merupakan salah satu dari metode multi faktor yang mampu melakukan proses analisis terhadap elemen yang besar. Karena kemudahan dan kecepatan dalam prosesnya, metode MFEP menjadi salah satu metode yang popular dalam sistem pendukung keputusan. Dalam prosesnya, sebuah factor/elemen terlebih dahulu dinilai secara kuantitatif pengaruhnya dengan menimbang subjektifitas dan intuitif terhadap alternative pilihannya [10]. Sehingga metode MFEP tepat digunakan dalam sebuah pengambilan keputusan yang memiliki elemen yang besar yang bersifat kuantitatif. Dalam perhitungannya, metode MFEP memilki prosedur sebagai berikut:

1. Penentuan kriteria Penting (Weight Factor)

Kriteria ditentukan oleh manajemen berdasarkan kepentingan suatu promosi jabatan.

2. Pemberian Bobot

3. Menentukan nilai bobot pada setiap faktor kepentingan dengan rumus $\mathrm{WF}_{1}+\mathrm{WF}_{2}+\mathrm{WF}_{3}+\ldots . .+\mathrm{WF}_{\mathrm{n}}=1$

Dimana:

$\mathrm{WF}_{\mathrm{n}}=$ Weight Factor ke-n

Dengan ketentuan bahwa nilai total pembobotan setiap factor kepentingan adalah $1(\Sigma$ pembobotan $=1)$.

4. Evaluasi Factor Weight Data evaluasi faktor penting dari tiap alternatif dapat dianalisis dengan menggunakan rumus $\mathrm{x}=\left(\mathrm{WF}_{1} * \mathrm{a}_{11}\right)+\left(\mathrm{WF}_{2} * \mathrm{a}_{21}\right)+\left(\mathrm{WF}_{3} * \mathrm{a}_{31}\right)+$ $\ldots+\left(\mathrm{WF}_{\mathrm{n}} * \mathrm{a}_{\mathrm{n}}\right)$

Di mana:

$\mathrm{x}=$ Weight Evaluation

$\mathrm{WF}=$ Weighted Factor

$\mathrm{a}=$ Evaluation Factor $\mathrm{n}=$ Jumlah Faktor

5. Menghitung Total Weighted Evaluation $\mathrm{X}=(\mathrm{x} 1+\mathrm{x} 2+\mathrm{x} 3+\ldots \ldots) / \mathrm{n}$ dimana:

$\mathrm{X}=$ Total Weighted Evaluation

$\mathrm{x}=$ Weighted Evaluation

$\mathrm{n}=$ Jumlah Faktor

\section{METODE}

Berikut ini adalah prosedur pelaksanaan dalam penelitian agar pelaksananan berjalan sistematis.

1. Studi Pendahuluan

Kegiatan penelitian diawali dari melakukan kajian kepustakaan dan melakukan observasi awal terkait dengan bantuan siswa miskin dan SPK metode AHP dan MFEP. Penyusunan Instrumen

2. Penyusunan instrumen

Penyusunan instrumen didasarkan sebagai alat yang akan digunakan dalam pengumpulan data.

3. Pengumpulan Data

Pegumpulan data dilakukan menggunakan instrument yang tekah dilakkukan ujicoba. Pengumpulan data dilakukan untuk mendapatkan data bobot kriteria dan bobot alternatif.

4. Analisis Data

Analisis dilakukan melalui 2 metode SPK yaitu AHP dan MFEP. Analisis menggunakan metode AHP untuk mendapatkan informasi berupa kriteria yang tingkat kepentingan suatu kriteria dalam mempengaruhi keputusan dalam penentuan penerima bantuan siswa miskin. Metode MFEP untuk mendapatkan nilai preferensi dari alternatif yang disusun dalam bentuk perangkingan. 
DOI: https://doi.org/10.33330/jurteksi.v6i2.597

Available online at http://jurnal.stmikroyal.ac.id/index.php/jurteksi

\section{HASIL DAN PEMBAHASAN}

Berdasarkan hasil observasi dan pengumpulan data di SMPS Tamansiswa Sukadamai, ada beberapa 4 faktor atau kriteria yang menjadi acuan dalam peningkatan kualitas penerima bantuan siswa miskin yang akan dilakukan analisis melalui penerapan metode AHP. Adapun kriteria penerima BSM tersebut pada tabel 2.

Tabel 2. Kriteria

\begin{tabular}{cl}
\hline Kriteria & \multicolumn{1}{c}{ Keterangan } \\
\hline $\mathrm{C} 1$ & Penghasilan Ortu \\
\hline $\mathrm{C} 2$ & Jumlah Tanggungan \\
\hline $\mathrm{C} 3$ & Absensi \\
\hline $\mathrm{C} 4$ & Nilai Rata-Rata Rapor \\
\hline
\end{tabular}

Berikutnya dalam menganalisa kriteria tersebut dalam metode AHP dimulai dari membentuk matriks perbandingan kriteria seperti pada tabel 3.

Tabel 3. Matriks Perbandingan Kriteria

\begin{tabular}{ccccc}
\multicolumn{5}{c}{ Kriteria } \\
\hline & C1 & C2 & C3 & C4 \\
\hline C1 & 1,000 & 7,000 & 0,333 & 4,000 \\
\hline C2 & 0,143 & 1,000 & 0,125 & 0,333 \\
\hline C3 & 3,000 & 8,000 & 1,000 & 7,000 \\
\hline C4 & 0,250 & 3,000 & 0,143 & 1,000 \\
\hline & 4,393 & 19,000 & 1,601 & 12,333 \\
\hline
\end{tabular}

Tabel 4. Sistesis Perbandingan Kriteria

\begin{tabular}{cccccc}
\hline \multicolumn{3}{c}{ Jumlah Setiap Elemen } & Jumlah & $\begin{array}{c}\text { Rata- } \\
\text { Rata }\end{array}$ \\
\hline 0,228 & 0,368 & 0,208 & 0,324 & 1,129 & 0,282 \\
\hline 0,033 & 0,053 & 0,078 & 0,027 & 0,190 & 0,048 \\
\hline 0,683 & 0,421 & 0,625 & 0,568 & 2,296 & 0,574 \\
\hline 0,057 & 0,158 & 0,089 & 0,081 & 0,385 & 0,096 \\
\hline
\end{tabular}

Berikutnya melakukan perhitungan setiap elemen dengan jumlah elemen dan rata-rata yang membentuk tabel sintesis yang akan menjadi landasan dalam perankingan kriteria seperti pada tabel 4.

Selanjutnya melakukan perhitungan Consistensi Rasio (CR). CI $=(\lambda$ maks-n)/n, Di mana $n=$ banyaknya elemen

$\lambda$ maks $=(0,282 * 4,393)+(0,048 * 19,000)+$

$$
(0,574 * 1,601)+(0,096 * 12,333)
$$

$$
=4,250
$$

$\mathrm{n} \quad=4$

CI $=(4,250-4) /(4-1)=0,083$

$\mathrm{IR}=0,90$ karena $\mathrm{n}=4$

$\mathrm{CR}=\mathrm{CI} / \mathrm{IR}=0,083 / 0,90=0,092$

Dari nilai $\mathrm{CR}=0,092$ tersebut, maka dapat dipastikan telah memenuhi syarat $\mathrm{CR}<0,1$ bahwa proses analisa prioritas kriteria yang mempengaruhi penerima bantuan siswa miskin dikatakan konsisten.

Tahapan berikutnya dari hasil proses metode AHP yang membentuk faktor prioritas akan menjadi Weight Factor (WF) dalam metode MFEP.

Tabel 5. Weight Factor (WF)

\begin{tabular}{cccccc}
\hline Factor & C1 & C2 & C3 & C4 & WF \\
\hline Weight & 0,282 & 0,048 & 0,574 & 0,096 & 1 \\
\hline
\end{tabular}

Tahapan penelitian berikutnya adalah menentukan alternatif-alternatif pene-rima bantuan siswa miskin. Adapun Sampel alternatif yang diambil berjumlah 20 dan diuraikan dalam A1 sampai A20 yang menjadi acuan proses penerapan MFEP untuk perankingan tertuang pada tabel 6 .

Langkah berikutnya menghitung Weighted Evaluation (x) dengan mengalikan nilai alternatif dengan Weight Factor (WF) seperti pada tabel 7. 
JURTEKSI (Jurnal Teknologi dan Sistem Informasi)

Vol. 6 No. 2, April 2020, hlm. 179 - 186

DOI: https://doi.org/10.33330/jurteksi.v6i2.597

Available online at http://jurnal.stmikroyal.ac.id/index.php/jurteksi
ISSN 2407-1811 (Print)

ISSN 2550-0201 (Online)
Tabel 6. Nilai Alternatif

\begin{tabular}{|c|c|c|c|c|}
\hline $\mathrm{A} / \mathrm{C}$ & $\mathrm{C1}$ & $\mathrm{C2}$ & C3 & $\mathrm{C4}$ \\
\hline $\mathrm{A} 1$ & 4 & 5 & 4 & 4 \\
\hline $\mathrm{A} 2$ & 2 & 5 & 3 & 5 \\
\hline A3 & 3 & 4 & 3 & 5 \\
\hline A4 & 3 & 3 & 3 & 5 \\
\hline A5 & 2 & 2 & 2 & 4 \\
\hline A6 & 5 & 3 & 4 & 5 \\
\hline A7 & 4 & 4 & 3 & 3 \\
\hline A8 & 3 & 3 & 4 & 5 \\
\hline A9 & 3 & 4 & 5 & 5 \\
\hline A10 & 2 & 4 & 5 & 5 \\
\hline A11 & 3 & 3 & 2 & 4 \\
\hline A12 & 4 & 2 & 3 & 3 \\
\hline A 13 & 5 & 2 & 3 & 4 \\
\hline A14 & 3 & 3 & 4 & 4 \\
\hline A 15 & 2 & 4 & 5 & 3 \\
\hline A16 & 2 & 3 & 5 & 4 \\
\hline A 17 & 3 & 4 & 4 & 5 \\
\hline A18 & 3 & 5 & 4 & 5 \\
\hline A19 & 5 & 4 & 3 & 4 \\
\hline A20 & 2 & 3 & 3 & 5 \\
\hline
\end{tabular}

Berdasarkan hasil Weighted Evaluation (x) pada tabel 7, langkah akhir dari metode MFEP adalah menghitung total Weighted Evaluation (x) seperti pada tabel 8. Metode MFEP dapat menentukan alternatif terbaik siswa yang layak sebagai penerima bantuan siswa miskin dengan nilai tertinggi yaitu A9 dengan 1,097.

Hasil analisis ini juga didukung oleh penelitian sebelumnya yang menyatakan dengan penggunaan metode AHP dan MFEP dapat membantu peternak alam menentukan factor utama dalam pemilihan bibit sapi potong terbaik [11].

Tabel 7. Weighted Evaluation (x)

\begin{tabular}{ccccc}
\hline A/C & $\mathbf{C 1}$ & $\mathbf{C 2}$ & $\mathbf{C 3}$ & $\mathbf{C 4}$ \\
\hline A1 & 1,128 & 0,24 & 2,296 & 0,384 \\
\hline A2 & 0,564 & 0,24 & 1,722 & 0,48 \\
\hline A3 & 0,846 & 0,192 & 1,722 & 0,48 \\
\hline A4 & 0,846 & 0,144 & 1,722 & 0,48 \\
\hline A5 & 0,564 & 0,096 & 1,148 & 0,384 \\
\hline A6 & 1,41 & 0,144 & 2,296 & 0,48 \\
\hline A7 & 1,128 & 0,192 & 1,722 & 0,288 \\
\hline A8 & 0,846 & 0,144 & 2,296 & 0,48 \\
\hline A9 & 0,846 & 0,192 & 2,87 & 0,48 \\
\hline A10 & 0,564 & 0,192 & 2,87 & 0,48 \\
\hline A11 & 0,846 & 0,144 & 1,148 & 0,384 \\
\hline A12 & 1,128 & 0,096 & 1,722 & 0,288 \\
\hline A13 & 1,41 & 0,096 & 1,722 & 0,384 \\
\hline A14 & 0,846 & 0,144 & 2,296 & 0,384 \\
\hline A15 & 0,564 & 0,192 & 2,87 & 0,288 \\
\hline A16 & 0,564 & 0,144 & 2,87 & 0,384 \\
\hline A17 & 0,846 & 0,192 & 2,296 & 0,48 \\
\hline A18 & 0,846 & 0,24 & 2,296 & 0,48 \\
\hline A19 & 1,41 & 0,192 & 1,722 & 0,384 \\
\hline A20 & 0,564 & 0,144 & 1,722 & 0,48 \\
\hline & & & &
\end{tabular}


DOI: https://doi.org/10.33330/jurteksi.v6i2.597

Available online at http://jurnal.stmikroyal.ac.id/index.php/jurteksi

Tabel 8. Weighted Evaluation (x)

\begin{tabular}{clc}
\hline $\mathbf{X}$ & \multicolumn{1}{c}{ WE } & Ranking \\
\hline XA1 & $=(1,128+0,24+2,296+0,384) / 4=1,012$ & $\mathbf{4}$ \\
\hline XA2 & $=(0,564+0,24+1,722+0,48) / 4=0,752$ & $\mathbf{1 7}$ \\
\hline XA3 & $=(0,846+0,192+1,722+0,48) / 4=0,810$ & $\mathbf{1 4}$ \\
\hline XA4 & $=(0,846+0,144+1,722+0,48) / 4=0,798$ & $\mathbf{1 6}$ \\
\hline XA5 & $=(0,564+0,096+1,148+0,384) / 4=0,548$ & $\mathbf{2 0}$ \\
\hline XA6 & $=(1,41+0,144+2,296+0,48) / 4=1,083$ & $\mathbf{2}$ \\
\hline XA7 & $=(1,128+0,192+1,722+0,288) / 4=0,833$ & $\mathbf{1 3}$ \\
\hline XA8 & $=(0,846+0,144+2,296+0,48) / 4=0,942$ & $\mathbf{9}$ \\
\hline XA9 & $=(0,846+0,192+2,87+0,48) / 4=1,097$ & $\mathbf{1}$ \\
\hline XA10 & $=(0,564+0,192+2,87+0,48) / 4=1,027$ & $\mathbf{3}$ \\
\hline XA11 & $=(0,846+0,144+1,148+0,384) / 4=0,631$ & $\mathbf{1 9}$ \\
\hline XA12 & $=(1,128+0,096+1,722+0,288) / 4=0,809$ & $\mathbf{1 5}$ \\
\hline XA13 & $=(1,41+0,096+1,722+0,384) / 4=0,903$ & $\mathbf{1 2}$ \\
\hline XA14 & $=(0,846+0,144+2,296+0,384) / 4=0,918$ & $\mathbf{1 1}$ \\
\hline XA15 & $=(0,564+0,192+2,87+0,288) / 4=0,979$ & $\mathbf{6}$ \\
\hline XA16 & $=(0,564+0,144+2,87+0,384) / 4=0,991$ & $\mathbf{5}$ \\
\hline XA17 & $=(0,846+0,192+2,296+0,48) / 4=0,954$ & $\mathbf{8}$ \\
\hline XA18 & $=(0,846+0,24+2,296+0,48) / 4=0,966$ & $\mathbf{7}$ \\
\hline XA19 & $=(1,41+0,192+1,722+0,384) / 4=0,927$ & $\mathbf{1 0}$ \\
\hline XA20 & $=(0,564+0,144+1,722+0,48) / 4=0,728$ & $\mathbf{1 8}$ \\
\hline
\end{tabular}

\section{UCAPAN TERIMA KASIH}

Penelitian ini dibiayai sepenuhnya oleh Kementerian Riset Dan Teknologi/Badan Riset Dan Inovasi Nasional melalui Deputi Bidang Penguatan Riset Dan Pengembangan Sesuai dengan Kontrak Penelitian Tahun Anggaran 2020.

\section{SIMPULAN}

Berdasarkan hasil analisis dari kombinasi metode AHP dan MFEP yang telah dilakukan yaitu Peneliti dapat mengambil sebuah kesimpulan bahwa metode AHP dapat membantu sekolah dalam menentukan faktor utama yang sangat prioritas dalam penerima bantuan siswa miskin. Metode MFEP dapat menentukan alternatif terbaik siswa yang layak sebagai penerima bantuan siswa miskin dengan nilai tertinggi yaitu A9 dengan 1,097.

\section{DAFTAR PUSTAKA}

[1] E. Suryani, "Sistem Pendukung Keputusan Penerima Bantuan Siswa Miskin Menerapkan Metode WASPAS dan MOORA," Semin. Nas. Sains Teknol. Inf., pp. 719-727, 2018.

[2] D. Assrani, N. Huda, R. Sidabutar, I. Saputra, and O. K. Sulaiman, "Penentuan Penerima Bantuan Siswa Miskin Menerapkan Metode Multi 
DOI: https://doi.org/10.33330/jurteksi.v6i2.597

Available online at http://jurnal.stmikroyal.ac.id/index.php/jurteksi

Objective Optimization on The Basis of Ratio Analysis (MOORA)," JURIKOM (Jurnal Ris. Komputer), vol. 5, no. 1, pp. 1-5, 2018.

[3] S. Suginam, E. S. Nasution, S. U. Lubis, and M. Mesran, "Sistem Pendukung Keputusan Penerima Bantuan Siswa Miskin Menerapkan Metode WASPAS dan MOORA," in Seminar Nasional Sains dan Teknologi Informasi (SENSASI), 2018.

[4] N. Rubiati, R. Kurniawan, and L. Septiana, "SISTEM PENDUKUNG KEPUTUSAN PENERIMA BANTUAN SISWA MISKIN (BSM) DI SDN 005 BUKIT TIMAH DENGAN MENGGUNAKAN METODE ANALYTICAL HIERARCY PROCESS (AHP)," Informatika, vol. 11, no. 2, pp. 37-43, 2019.

[5] K. Fasya, F., Arifin, M. Z., Muttaqin, Z., Sukur, R. S., \& Kusrini, "Penerapan Metode Profile Matching Pada Sistem Pendukung Keputusan Untuk Memilih Calon Penerima Beasiswa Bidikmisi," CAHAYAtech, vol. 7, no. 1, pp. 50-61, 2018.

[6] E. Yulianti and Y. A. Nurdin, "SISTEM PENDUKUNG KEPUTUSAN PENERIMAAN BANTUAN SISWA MISKIN (BSM) BERBASIS ONLINE DENGAN METODE KNN (KNEAREST NEIGHBOR)(Studi kasus: SMPN 1 Koto XI Tarusan)," J. TeknoIf, vol. 6, no. 1, 2018.

[7] A. P. Windarto, "Implementasi Metode Topsis Dan Saw Dalam Memberikan Reward Pelanggan," Klik - Kumpul. J. Ilmu Komput., vol. 4, no. 1, p. 88, 2017.

[8] J. Lemantara, N. A. Setiawan, and M. N. Aji, "Rancang Bangun Sistem Pendukung Keputusan Pemilihan Mahasiswa Berprestasi Menggunakan Metode AHP dan Promethee," Jnteti, vol. 2, no. 4, pp. 20-28, 2013.

[9] S. H. Saragih, "Penerapan Metode Analitycal Hierarchy Process ( Ahp ) Pada Sistem Pendukung Keputusan Pemilihan Laptop," Sylvia Hartati Saragih, pp. 82-88, 2013.

[10] M. R. Okaviana and R. Susanto, "Sistem Pendukung Keputusan Rekomendasi Pemilihan Program Studi Menggunakan Metode Multifactor Evaluation Process Di Sma Negeri 1 Bandung," Komputa J. Ilm. Komput. dan Inform., vol. 3, no. 2, pp. 50-57, 2014.

[11] A. Afrisawati and I. Irianto, "PEMILIHAN BIBIT TERNAK SAPI POTONG MELALUI KOMBINASI METODE AHP DAN METODE MFEP," Jurteksi, vol. 6, no. 1, pp. 43-50, 2019. 